\title{
Local Norms for Gifted and Talented Student Identification: \\ Everything you Need to Know
}

\begin{abstract}
Conversations over who should be identified as gifted continue perpetually both within the field and in the popular media. In this paper, we focus on the use of local norms as one approach to gifted identification that can increase the equity of advanced educational programs and services while also better achieving their stated purpose of providing additional challenge to those students who need it. In this paper, we define local norms, explain their purpose, provide examples of schools who have used local norms, discuss common challenges, and provide a tutorial and external resources on how schools can begin to use local norms as part of their gifted identification process.

Scott J. Peters

Professor of Assessment and Research Methodology

University of Wisconsin - Whitewater

800 W. Main St. Whitewater, WI 53190

262-472-5407

peterss@uww.edu

Matthew C. Makel

Johns Hopkins University

Karen Rambo-Hernandez

Texas A\&M University

Word count: 8789

Keywords: Giftedness, Identification, Local Norms, Equity
\end{abstract}

Version of record:

Peters, S. J., Makel, M. C., \& Rambo-Hernandez, K. (2021). Local norms for gifted and talented student identification. Everything you need to know. Gifted Child Today, 42(2), 93-103. https://doi.org/10.1177/1076217520985181 
Local Norms for Gifted and Talented Student Identification:

\section{Everything you Need to Know}

Conversations over who should be identified as gifted continue perpetually both within the field and in the popular media. These conversations often focus on which test to use, whether to use referrals or nominations, whether to use classroom performance as opposed to standardized tests, and even whether students should be identified at all. These questions become even more complicated when multiple measures are considered and when the answers to these questions carry implications for equity. Our goal with this paper is to focus on one particular identification procedure that we have seen increase the equity of advanced educational programs and services while also helping schools challenge a wider range of learners.

The practice to which we refer is the use of local norms to identify gifted and talented students. We designed this paper in three sections. First, we introduce what local norms are, who should use them, and provide several examples where districts have used local norms to positive effect. Second, we outline and respond so some of the most common concerns raised by teachers and administrators related to local norms. This list includes the option of a compromise rule where schools continue to use national norms while also adding a local norm pathway. This is not an exhaustive list, but should help prepare districts interested in implementing local norms for the first time. Third, we include a how to section, including an Excel template and accompanying instructional video, to help educators implement local norms. We approached this manuscript assuming little prior knowledge and with the purpose of being a practical resource for those who are curious to those who are ready to implement local norms. As a result, readers are likely to find various sections to be more relevant to their point in the journey than others. We designed each section somewhat to stand alone so readers can attend to the sections more relevant to their specific needs. 


\section{What are Local Norms?}

Every year, schools across the country hold tryouts for their athletic teams with the best players making the team. Subsequently, all-conference, all-state, and all-American teams are selected - each at a different level of competition. As the context changes, so do the criteria by which players are selected. Imagine if a school's soccer coach decided that only players who perform equivalent to All-American caliber would make the team. Students who are below that threshold do not make the team, even if that means the school will not field a team that year. We suspect this would be wildly unpopular and the coach would be forced to change course or else would find him- or herself out of a job. Yet, this All-American approach is precisely the type of selection process used by schools across the country for their gifted programs. Regardless of the context of the school, only those students who meet a pre-set, national-norm criteria are selected.

Typically, athletic teams rely on local norms for selecting players. Teams are comprised of the top players at the school (at least among those who try out for the team). This can lead to teams of varying skill levels across schools or even within a school across different years. Some years the pool of potential players is very strong while others require a lot of support the coach is not used to having to provide. But that is the job of a coach - to develop the talent at that particular school. How that talent compares to the level of talent at a neighboring school is irrelevant. This same analogy applies to auditions for the school musical, forensics team, or orchestra.

As we will describe, using local norms for the identification of gifted students may feel like a cultural shift. But, as demonstrated by athletics (and the school band, orchestra, plays, and musicals), the concept of applying local norms for a local program is not wholly foreign in the school setting. In fact, it is more the rule than the exception. Professional Organizations (American Educational Research Association, American Psychological Association, \& National Council for Measurement in Education, 2014) as well as advocacy groups (Yaluma \& Tyner, 
2018) have argued for purposeful applications of local norms in certain contexts - just as we do here.

\section{Norms in the Gifted Education Context}

Any time an assessment is given to a student, the results could interpreted one of two ways: either a criterion-referenced interpretation or a norm-referenced interpretation. This applies to a standardized test score or a student's final project in a pottery class. From the criterion-referenced perspective, a student's performance is compared to a pre-set standard such as an instructional objective. For example, a student's performance on a state achievement test is often compared to state standards at each grade level in order to determine if she has met those standards. That is a criterion-referenced interpretation of her performance. Alternatively, a teacher could apply a norm-referenced interpretation where the only concern is comparison to peers - what percentage of fellow test takers did the student perform better or worse than? Often this takes the form of high school class rank or percentile scores. A student's standardized test report might list the skills she has mastered (criterion-based), but also list how many students mastered fewer skills (her percentile). Similarly, Carlos might be the best soccer player on the team this year (norm-referenced), but still not an especially strong soccer player (criterion-referenced). Neither interpretation is right or wrong - they are different ways of understanding the same piece of information.

Historically, gifted and talented student identification has been norm based. Students are identified if they score better than a certain percentage of their peers - often a high percentage such as $95 \%$ or $98 \%$. Although often left unsaid, such norm-based identification policies tend to imply national norms, where the student must score higher than $98 \%$ of age- or grade-peers across the country. Arizona is an example of where a state policy makes national norms more explicit: "School districts....shall identify as gifted at least those pupils who score at or above the ninety-seventh percentile, based on national norms, on a test adopted by the state board of education" (Arizona State Legislature, n.d., 1.A.). Although we know of no data on how common 
national-norm criteria are for gifted and talented student identification, we feel confident saying it is the dominant paradigm. Often using national norms is just assumed or taken for granted by school districts. Test score reports often include a student's national norm percentile so it is easily accessible. But why national norms and not some other type of normative comparison for gifted and talented identification? Do such data provide educators with the information they need to challenge a wider range of learners?

Some states mandate or allow for norms other than national to be used for identification. Illinois is a good example:

Gifted and talented children. For purposes of this Article, "gifted and talented children" means children and youth with outstanding talent who perform or show the potential for performing at remarkably high levels of accomplishment when compared with other children and youth of their age, experience, and environment. A child shall be considered gifted and talented in any area of aptitude, and, specifically, in language arts and mathematics, by scoring in the top 5\% locally in that area of aptitude. (Illinois General Assembly, 2005, p. 1, emphasis added).

In this case, students are identified as gifted if they score in the top $5 \%$ of the students in their grade in their local school building. New Jersey has a similar requirement in its administrative code:

'Gifted and talented students' means students who possess or demonstrate high levels of ability in one or more content areas when compared to their chronological peers in the local school district and who require modifications of their educational program if they are to achieve in accordance with their capabilities. (New Jersey Department of Education, 2018, p. 4, emphasis added).

In both cases it is not a national normative comparison that is called for but rather a local, within-building comparison that should be used for gifted student identification. 
Many states do not specify a norm group. Some states give general definitions for gifted but do not prescribe how high a person's ability or achievement need to be to qualify. In such a situation, how should a norm group be selected? As a general rule, we believe programs should align their selection criteria with the level of service they seek to provide. If a program seeks to serve the top performing students in a school building, then building-level norms make the most sense for identification purposes. Similarly, if a program seeks to identify the top students in the nation, then national norms make sense.

\section{Why Use Local Norms?}

Local norms should be used to identify students for within-building advanced academic interventions for two reasons:

1) Local norms better align with conceptual definitions of gifted in K-12 schools; and

2) If implemented at scale, local norms would result in greatly-improved equity within identified gifted populations.

We address each of these in turn.

\section{Greater Conceptual Alignment.}

First, if practitioners want to follow common state or national definitions of who is gifted then they should turn to local norms for local services. This is true even outside of the two localnorm friendly definitions from Illinois and New Jersey cited above. For example, consider the most recent Federal definition from the No Child Left Behind Act:

Gifted and talented.--The term "gifted and talented", when used with respect to students, children, or youth, means students, children, or youth who give evidence of high achievement capability in areas such as intellectual, creative, artistic, or leadership capacity, or in specific academic fields, and who need services or activities not ordinarily provided by the school in order to fully develop those capabilities. (No Child Left Behind, 2002, p. 115, emphasis added). 
This definition includes specific criteria for what constitutes gifted and talented: 1) the student must be capable of high achievement in a particular domain and 2) the student must require additional services not ordinarily provided by the school. To us, this implies a clear local norm reference group. The most recent National Association for Gifted Children definition is similar: "Students with gifts and talents perform - or have the capability to perform - at higher levels compared to others of the same age, experience, and environment in one or more domains (NAGC, 2019, p. 1, emphasis added). The emphasized clause in this definition is common, often overlooked by gifted identification policies, and aligns with a local norms perspective. Students are often identified if they score at advanced levels (are "capable of high achievement") without any consideration for how that advanced level of achievement compares to his or her instructional environment. The NAGC definition emphasizes that policies should compare a student's performance to others of similar age, experience, or environment to determine who should be identified for services. That local context can be the student's school. After all, K-12 gifted education is a kind of intervention for those who need it to be appropriately challenged (see Peters \& Borland, in press). From this view, knowing who is advanced compared to students across the country is not relevant or helpful. It fails to identify who is underchallenged in the regular classroom or might require supplementary services. Local norms, although still not perfect, are better at answering the question of who in a given learning environment is most likely to be underchallenged and require additional interventions.

Thus far, we have spent a lot of time discussing why a school should use local norms to identify students. What we have not addressed is for what students would be identified. A good identification system should correctly identify all of the students who have a need for-and would benefit from-a particular intervention. This means that an identification system must depend on the intervention to be provided. Also, this is why the level of the norm should match the level of the service. Full-grade acceleration should follow a different identification protocol than within-class enrichment or cluster grouping. Applying local norms will tell educators at a 
particular school which students are the most advanced compared to their grade-level peers in the same school. Viewed another way, they will identify which students are most likely to require additional interventions in order to be challenged. We say most likely because it is possible more students will go under challenged without additional intervention. It is also possible that all of the students in a given grade level are perfectly challenged through existing service. All local norms do is identify which students are the most extreme compared to their peers and therefore likely to require content that is different from those peers. We will address the question of "which content?" or "which services?" in the Common Challenges section below.

\section{Greater Equity}

A second reason to use local norms is that they would result in an identified gifted population that is much more-closely representative of the demographics of American schools (Peters et al., 2019a, Plucker \& Peters, 2016). Although the following section shares examples of where this was observed in real school districts, we want to emphasize that local norms are only part of a larger model of combatting inequity in gifted education and excellence gaps more broadly. Plucker and Peters argued that in addition to local norms, frontloaded educational experiences are particularly important to closing opportunity gaps that are at the heart of disproportionality.

Recently, one of us was working with a large school district that had been applying national norms for identification purposes. Students needed to score two standard deviations above the national average (roughly the top $2.25 \%$ ) to be identified as gifted. In Table 1, the demographics of the population of students identified under this criterion are in the "current practice" column. The second column shows the demographics if a local norm of the top $15 \%$ were applied, and the final column shows the overall student population demographics.

\section{Table 1}

District Demographics Compared to National and Local Norm Demographics 


\begin{tabular}{lccc}
$\begin{array}{c}\text { Race / } \\
\text { Ethnicity }\end{array}$ & District Population & $\begin{array}{c}\text { Current } \\
\text { Practice of } \\
\text { National } \\
\text { Norms }\end{array}$ & $\begin{array}{c}\text { Local Norm of } \\
\text { Top 15\% of } \\
\text { School }\end{array}$ \\
\hline $\begin{array}{l}\text { European } \\
\text { American }\end{array}$ & $38.9 \%$ & $42.6 \%$ & $44.7 \%$ \\
$\begin{array}{l}\text { African } \\
\text { American }\end{array}$ & $9.6 \%$ & $2.3 \%$ & $4.9 \%$ \\
Latinx & $25.7 \%$ & $4.7 \%$ & $12.7 \%$ \\
$\begin{array}{l}\text { Native } \\
\text { American }\end{array}$ & $0.3 \%$ & $0.2 \%$ & $0.4 \%$ \\
$\begin{array}{l}\text { Asian } \\
\text { American }\end{array}$ & $19 \%$ & $41.7 \%$ & $30.1 \%$ \\
Multi-Racial & $6 \%$ & $8.5 \%$ & $7.2 \%$ \\
\hline
\end{tabular}

Applying local norms in this district would increase African American identification by $213 \%$ and Latinx identification by $270 \%$. This does not result in perfect parity, but it is a giant leap toward equitable representation. It is also worth pointing out that in this case, AsianAmerican student representation decreased under local norms from $42 \%$ of the identified gifted population to $30 \%$. Even at $30 \%$ they are more than $150 \%$ as represented in the gifted population compared to the overall population. However, such a change may still cause some concern or controversy. We address this in greater depth in our section on common challenges.

In another case, Aurora Public Schools (Colorado), saw similar results with their pilot of local norms. The District's 40,000 students come from more than 130 countries and speak more than 160 languages. 36\% are English language learners, 55\% are Latinx, $18 \%$ are African American, and $15 \%$ are European American. Like so many other districts, identified gifted students were not demographically representative of the larger district population. This district had a second common problem in that most of the gifted kids came from a small cluster of schools while other schools had zero students identified as gifted.

This district was not ready to jump straight to full implementation of local norms across every school, so it implemented a pilot program with ten elementary schools that had a history 
of low gifted identification rates and large identification gaps between groups. Before the local norm pilot, Latinx students were underrepresented by 17 percentage points. As a result of the pilot, Latinx students are still underrepresented, but only by 7 percentage points. Rates of underrepresentation shrank for other groups as well: African American underrepresentation went from 6 percentage points to only 2 and European American students went from a proportional overrepresentation of 24 percentage points to only 6 percentage points. All groups made progress toward greater proportionality.

The local norm pilot was so successful that the district is now expanding it to a second set of ten schools while also reflecting on what programmatic changes will be needed to be culturally sensitive and meet the needs of its newly-identified students - key components of any larger model designed to combat excellence gaps (Plucker \& Peters, 2016, Plucker et al., 2017). As we will describe in greater detail below, with any differentiated identification system comes a need to differentiate services, including through culturally-relevant teacher training. If a district is not ready to jump straight into local norms, a small pilot (in a few schools or as one potential pathway) can be used to test the concept and work out any challenges before moving forward in the entire district.

Another example of the effects of using local norms comes from a 2018 study by Carman et al. The authors investigated how applying local norms to the nonverbal battery of the Cognitive Abilities Test would influence the representation of the identified population in the Houston Independent School District. Again, as shown in Table 2, local norms had a dramatic effect on representation within gifted education, even more pronounced than in the prior example.

Table 2

Identified Gifted Demographics under National and Local Norms

\begin{tabular}{llcc}
$\begin{array}{l}\text { Student } \\
\text { Group }\end{array}$ & $\begin{array}{c}\text { District } \\
\text { Population }\end{array}$ & $\begin{array}{c}\text { National } \\
\text { Norms }\end{array}$ & $\begin{array}{c}\text { Local } \\
\text { Norms }\end{array}$ \\
\hline
\end{tabular}




$\begin{array}{lccc}\text { European } & 7 \% & 23 \% & 10 \% \\ \text { American } & & & \\ \text { African } & 23 \% & 9 \% & 16 \% \\ \text { American } & 65 \% & 44 \% & 64 \% \\ \text { Latinx } & 3 \% & 21 \% & 9 \% \\ \text { Asian } & 80 \% & 46 \% & 74 \% \\ \text { American } & 46 \% & 40 \% & 52 \% \\ \text { Low-Income } & & & \\ \text { ELL } & & \end{array}$

Table 2 shows that a move from national to local norms would essentially eliminate underrepresentation for Latinx students and students who are still learning English (ELL) and double representation for African American students in gifted programs. Local norms would also come close to eliminating underrepresentation for students who were eligible for free or reduced-price meals. This case from Houston is one of the best-case examples where a simple change in identification criteria yields substantial equity benefits in gifted identification.

Although tests used in the prior examples were both general school ability and nonverbal ability tests, the type of test does not appear to influence the capacity of local norms to improve equity in gifted identification. Peters et al. (2019a) investigated the effect of moving to local building norms for identification at a much larger scale-using a database of more than three million students across ten states. In this case, the data were from math and reading achievement tests. They found that a move from a national norm of the top $5 \%$ to a local building norm of the top $5 \%$ would more than triple African American student representation in reading and quadruple it in math. For Latinx students, local norms would more than double representation in both reading and math. It is important to note that both groups would still be disproportionately underrepresented as gifted in either math or reading, but that this simple change in identification criteria would result in drastic equity benefits with little additional cost in terms of testing. The important takeaway is that across multiple contexts, different types of 
school districts, and different types of tests, local norms have shown an ability to increase equity in identified gifted and talented populations.

Although the previous section deals with equity benefits, we want to emphasize again that local building norms identified the students most likely in need of additional challenge. Such an application of local norms is most appropriate for within-building services like placement in the gifted or high achieving cluster class. Other advanced learning services, such as full-grade acceleration or placement in a district-wide magnet program for advanced learners should rely on norms at a different level (e.g., district or national norms).

\section{Common Challenges and Stakeholder Concerns}

In our experience, local norms can seem a lot more complicated than they actually are. The calculations or rank-ordering of scores is fairly simple once the data are all in one place. We outline the process in the final section of this paper. What is more challenging is the roll-out, communicating with parents and families, and thinking through the implications for services. A good maxim for anyone seeking to improve the equity of any advanced educational program (e.g., gifted education, honors math classes) is that nothing in life is free. Although local norms are a low-cost intervention for improving equity of identification rates, there are challenges that need to be overcome, expanded services that will be needed, and parent concerns that will need to be addressed. In the following section we respond to some of the most common concerns we have heard from teachers, parents, and administrators about local norms.

1. Under local building norms, could a lower-scoring student be identified as gifted while her higher-scoring peer is not? Simply due to which school the two students attend?

Absolutely. We saw this with a school district in Illinois. Table 3 shows the cut scores on the reading and math achievement test for the nation (national norm of 90 th percentile), the district (what score it would take to be at the 90th percentile in the district), and at each building (local 90th percentile norm). 
Table 3

Average Reading and Math Achievement Test Scores by Elementary Building

\begin{tabular}{ccc}
\hline Building & $\begin{array}{c}\text { Reading } \\
\mathbf{9 0}^{\text {th }} \\
\text { Percentile }\end{array}$ & $\begin{array}{c}\text { Math } \mathbf{9 0}^{\text {th }} \\
\text { Percentile }\end{array}$ \\
\hline Nation & 569 & 703 \\
District & 632 & 699 \\
\hline Larson & 627 & 663 \\
Middle & 565 & 668 \\
Orland & 649 & 700 \\
Roosevelt & 643 & 711 \\
Rockton & 592 & 666 \\
Wilson & 526 & 686 \\
\hline
\end{tabular}

This district has six elementary buildings that differ quite a bit from each other. If this district were to implement local norms, a student at Wilson could be identified as gifted in reading with a score of 530 - this would exceed the building 90th percentile. However, a student with a 530 at Roosevelt would not be identified as gifted in reading despite having mastered a higher level of reading. We list this as the first common concern because it tends to be the most common question we hear from people once they hear about local norms. Will parents be understandably upset by this? Will this be a logistical nightmare? What if the student moved from Wilson to Roosevelt? He was gifted back in Wilson but has been de-gifted now that he moved across town? These are all perfectly reasonable questions.

We need to make clear that we see local norms as identifying students for advanced academic interventions and not as diagnosing students as gifted. However, for simplicity, we refer to students who are identified for advanced academic interventions using local norms as gifted. Whether giftedness is/should be viewed a fixed state is beyond the scope of the conversation here. Regardless, if the goal of gifted education is to determine who is most likely to require some kind of additional challenge due to the ordinary services or curriculum being insufficiently challenging (see definitions above), then it should come as little surprise that who is identified varies across schools. This happens all the time in schools for sports, music, and 
the arts. In our example, the student was identified in Wilson because his score of 530 placed him well above the average student at Wilson and, presumably, the ordinary classroom instruction. He was so far away from the typical student in that environment that he was likely to require something more. However, when he moves to Roosevelt, a 530 is not unusual. In fact, the level of readiness and achievement a 530 represents could be in line with most of his peers and with the regular classroom instruction. The result is a student who is challenged in reading in the regular grade-level classroom, hence no additional intervention is required. What is important is that regardless of whether or not a student is identified as gifted or meets the xxth percentile at a particular building, he should still be appropriately challenged. All students need to be appropriately challenged; it is just that some require an advanced academic intervention for that to happen. At Wilson, the student needed an advanced academic intervention to be appropriately challenged. At Roosevelt, the grade-level classroom was just fine. That is why different scores being required to be identified in different buildings can still be consistent with gifted identification.

\section{What about when the student moves to middle or high school?}

From a local norms perspective, moving from elementary to middle school is the same situation as when a student moves from one elementary school to another (like Wilson to Roosevelt). When a student changes schools, what is offered as part of the ordinary, gradelevel educational experience also changes. In one high school, Advanced Placement Calculus may be widely available. Because of this, a student need not be identified as gifted or receive special intervention to be appropriately challenged in mathematics. However, if this student moves to a different high school, that school might not offer any mathematics classes after geometry or algebra 2. Because of this level of ordinary math instruction, once the student moved schools, she may require supplemental service to be challenged. The overall thesis is that whether a child needs an additional service depends on what he or she is currently receiving as instruction and how well that aligns with her academic needs. 
We recommend school districts note how the students of various backgrounds are performing and participating in more advanced classes after they move from elementary school to middle school or high school. Anecdotally, some of the districts who had moved to local norms have noted students from certain underrepresented groups were opting out of services and advanced classes at much higher rates than students from more typically represented groups despite roughly equivalent performance. If this happens, it is a sign that some additional supports are needed to assure equitable student success. Remember, if a district is going to differentiate identification pathways, it must also be ready to differentiate services to best support students.

\section{How do we respond to concerns about local norms watering down the program?}

We want to emphasize that local norms are about identifying which students are most likely to require additional challenge. They should be used to identify students for a particular service, not to identify students for one general gifted program. As noted in Table 3, students who meet the identification criteria in each of these schools will require different services. In some buildings, clustering the advanced learners together to allow for greater depth of math instruction might be sufficient. In another building, the students who meet the local norm might require that the grade-level match instruction to be compacted as to cover two years of math content in one academic year. Services can and should vary based on the needs of the local students. We do not see this as watering down any more than it is watering down to provide bilingual or special education supports to students who require them. Local norms will diversify the students who are served by gifted interventions, and they will require that those services be differentiated, but this does not mean those services are any less rigorous.

\section{Does this mean we should de-gift kids if they move?}

In the cases of students moving elementary buildings, or moving from elementary to middle, students might no longer meet the criteria for an advanced learning intervention. Such a scenario might be a case where a student is identified as gifted at Wilson elementary, but then 
moves to Roosevelt where he is closer in performance to his peers and no longer requires supplemental intervention to be challenged. Does this mean he is no longer gifted?

Some of the districts we have worked with assign the gifted label to a student once he or she is identified and then leave that label for all time. However, the district changes whether the student receives a service based on local, ongoing criteria (such as local norms or recent performance). This way, the school is never in the position of de-gifting a child. The label and the service are decoupled and whether a student receives a specific service is not tied directly to whether the child is identified as gifted. Other schools have stopped using the gifted term altogether and simply identify students every year as in need of additional services or not. That way there is less of a concern about the label and more focus on providing appropriate level of service to each student. Regularly adding/removing a label can cause controversy and difficulty. Decoupling labelling from services or providing services without a formal label may avoid some of this difficulty. In either case, the district is never in the position of de-gifting a child.

5. The examples above show a decrease in the identification rates for some European-American and some Asian-American students. This could be a problem with some of the families whose kids would no longer qualify.

In the Carman et al. (2018) example from Houston, the district was 3.3\% AsianAmerican. Under national norms, $21 \%$ of identified gifted students were Asian-American whereas it went down to $9 \%$ under local norms. Under local norms Asian-American students were still disproportionately overrepresented by almost triple (3.3\% vs. $9 \%$ ), but it represents a significant decrease from national norms $(21 \%)$. It is unlikely that a district would all of a sudden de-gift students who had been previously identified under national norms, but it is still likely that large changes of students who had been identified previously would generate some concern. This gap between national and local norms occurs because there are large numbers of very high scoring Asian-American students who are concentrated in certain school buildings. This concentration results in many unquestionably high-scoring students who are Asian-American 
who, despite these high scores, cannot all score in the top $\mathrm{x} \%$ of their school. Peters et al. (2019a) found that a general trend with local norms is that all student groups move closer to proportionality. For African American and Latinx groups, this means an increased identification rate. For European-American and Asian-American groups, this often means a decreased identification rate.

There are multiple ways to respond to this decrease in disproportional overrepresentation. If schools simply implement local norms with no deviation, one challenge will be to explain this new system to parents and families whose children has previously been identified as gifted. A transition period where the new identification process is phased in may help make such a change more acceptable by parents. Alternatively, instead of only using only local norms, a district can implement a compromise plan where students are identified as gifted if they meet a local norm OR a national norm. A simpler way to think about the compromise rule is that it is a second pathway to identification. In the Peters et al. (2019a) study, when national norms were applied, approximately $3 \%$ of students were identified reading with about $3.5 \%$ in math. Under building norms these values were almost identical: $3 \%$ in reading and $3.4 \%$ in math. A move from national to local norms had almost no change in the size of the service population. However, under the compromise rule where students could be identified if they met the national OR the local norm (the second pathway), $4.3 \%$ of students were identified in reading and $5 \%$ were identified in math. This might not seem like a large change, but if a district has 5000 students in each grade level, then this increase is another 65 students to serve in reading and another 80 in math, which is about $40 \%$ more students being served under the compromise plan than under local norms alone. As we noted before, nothing in life is free. The cost for avoiding the decreased percentage of Asian-American and European-American students under local norms (via the compromise rule) is a larger overall gifted population. More gifted students might sound great, but these are more students who will then need to be served. 
Which option to pursue - local norms alone or the compromise rule - is up to the individual district. Both have characteristics that make them appealing as well as additional costs.

\section{Our state does not allow local norms. Are we out of luck?}

As we noted above, there are states like Arizona where the state criteria for gifted involves a national norm. There are also states like Florida or Oklahoma where a certain IQ score is required (a de facto national norm) or national percentile score is required (e.g., Oklahoma requires a score in the top $3 \%$ of a nationally standardized test of ability). When a state has such a definition, it is often for the purpose of assigning funding or mandating some kind of service. For example, in Oklahoma, the state provides per-pupil funding for every student who meets the state criteria, but these criteria are national norms. However, national norms being required for gifted service eligibility does not preclude the use of local norms for other services. A district could still use local norms to identify students for other advanced academic interventions. We have worked with districts in such cases where there are levels of services into which students are placed based on different criteria, such as local norms. The most advanced services might follow the state definition of gifted, whereas other services are based on a local norm.

7. What about the truly gifted kids? Local norms seem to focus gifted education on a different group of students.

As we articulated in the section on why local norms make conceptual sense with many definitions of gifted, we believe local norms, in the context of K-12 schools, would actually identify the right students - those most in need of additional challenge. However, this requires a shift for those with traditional views of what gifted means. A student with an IQ of 145 will almost always still be identified under local norms. This student will need a service very different than the child who has an IQ of 105, even if both are in the 99th percentile of their school. Local norms diversify the population of students identified as gifted. They are more diverse in terms of race, ethnicity, and income, but the side effect is they also have a wider range of learning needs 
than if a national norm or fixed cut score were to be used for identification. Implementing local norms does not mean students with extreme learning needs no longer exist or are well served by the same services. Some students identified via local norms will require small curricular modifications while others might require specific social-emotional supports as well as grade acceleration. Gifted was never meant to be a homogenous group with a single set of needs and implementing local norms would further diversify those needs.

\section{Shifting to local norms would be a massive shift for my school, how do I talk} about it with my colleagues?

As we have tried to model in this paper, schools use local norms for various activities (sports, selecting 1st chair clarinet, who gets the solo in the choir, or the lead in the school play). Because of this, the concept of local norms should be familiar to most school staff even if they do not often think of musical auditions as local norms. Similarly, as we have discussed throughout, the use of any norm should be aligned with the goals of a service. Framing the conversation around the goal of providing services to appropriately challenge students can be compelling. This framing around academic needs has the added benefit of framing the conversation around a goal that is likely universal across all students and a goal shared by all. Who does not want to appropriately challenge students? Similarly, coming equipped with the examples of the changes in demographic representation in gifted programs could also help demonstrate other benefits to using local norms. However, you should be sure not to promise that such changes will necessarily occur in your schools. Changes in demographic representation in who is identified as gifted will vary widely across schools and school districts. Finally, as demonstrated in an earlier example, trying a pilot application of local norms may foster greater comfort with trying local norms. Seeing how they look in your schools for a short period of time may help shift change in a more low-stakes manner. If even a pilot feels too big, then presenting colleagues with what the gifted program would have looked like using local norms in previous years may help. Using historical data, you could show who (and how many) 
would have been identified as gifted in your school or district. We show you how to do this in the next section.

\section{How to Implement Local Norms}

Before introducing how to use local norms, we need to return to something we wrote earlier on in this article. Local norms, like all norm-referenced interpretations, are a way of interpreting a data point. Nothing about local norms tells you what to measure, what data points from which tests you should include in an identification system, or what process should be used to collect identification data. Instead, local norms report who is the highest or lowest on those identification data within the local school. This means that the first thing you need to do is decide what data points (tests, observations, teacher ratings, etc.) to collect to make gifted identification decisions. Although we can reference a few sources that are good places to look for help in making this decision (e.g., Lee et al., 2020; Lohman, 2009; Peters et al., 2014), it is beyond of the scope of this article. Any number of data points can be used to make an identification decision via local norms. On one extreme this could be based on a single test score (IQ, CogAT composite score, etc.). In this case, local norms are simply a rank-ordering of that score. On the other extreme, is a system that relies on many different data points from many different sources. For example, in Alabama, all second-graders have some aptitude data point (e.g., Cognitive Abilities Test, Naglieri Nonverbal Ability Test) as well as three classroom performance tasks (scored by a rubric) and then a rating of gifted behaviors - five data points all on very different numerical scales. Both of these extremes and anything in-between can still be used with local norms. We explain how in the next section.

\section{Data Organization}

The first step is organizing your data so that all data points are available for all of students. This is often referred to as universal consideration. The process of local norming data will be easiest and most accurate if all data points are available for all students. This is because it is only possible to create a norm based on the data on hand. If you only have data on some of 
your students, then it is hard to say which of the students are the top performers in the overall group. If the policy will include data points available on some students, but not on all, then there will be some increase to both false negatives and false positives. This represents a case of missing data. The problem is that the impact such a scenario will have on the accuracy of the identification process depends on why the data are missing. If they are missing because they were only gathered on those students who performed highly on some other (related) test, then the impact will be smaller - such as a case where an IQ test was only given to those students who had high achievement test scores. However, if they are missing because the data were only gathered on students who were referred by their parents, then the increase to both false positives and false negatives will be greater. This is why it is always best to have all data points on all students.

\section{Calculating Local Norms}

Matt McBee (McBee and Peters, 2019) created a local norms implementation spreadsheet (hereafter referred to as "the spreadsheet") to help educators practice with and implement local norms. We have expanded on this spreadsheet by creating a narrated video of it along with screenshots to help in the implementation of local norms (LINK). The spreadsheet is free to download and use with your data; it contains background calculations that do much of the work for you (https://osf.io/2pqmi/). Although we refer to the spreadsheet to walk through the steps of calculating local norms, the spreadsheet is not necessary to do so; the same procedures can be done outside of the spreadsheet template.

\section{What Data Points to Include?}

As noted above, the first step is to decide what criteria to include in the identification process for a particular service. In the example above, we included percentile scores from the Cognitive Abilities Test, scale scores from a state achievement test, and the scale scores from a teacher rating of each student on common gifted characteristics. You can calculate a local norm 
on any number of assessments of any different type. However, what is measured should be related to the skills and abilities needed to succeed in the resulting service that will be provided.

\section{Creating a Common Scale}

When calculating a local norm, all of the data points must be brought onto a common scale. Scores can be reported an infinite number of ways to the end user. Regardless of how they exist in a database or come back from a testing company, the first step is to get them onto a common metric or scale. The spreadsheet does all this work. In our example, CogAT percentiles are included as well as scale scores from a teacher rating and scale scores (on a different scale!) from an achievement test. The "data" tab of the spreadsheet shows this example data. Even before any student data are entered, you need to identify if the data represent percentiles or if they are scores of some kind (e.g., IQ or CogAT scores with a mean of 100 and standard deviation of 15 or 16 ). You need only select from the dropdown menu in the second row of the spreadsheet to indicate whether a given data point is a percentile or a score. See Figure 1 below for the location of this dropdown.

\begin{tabular}{|c|c|c|c|c|c|c|c|c|c|c|}
\hline \multicolumn{11}{|c|}{ Show rows with cells including: } \\
\hline \multirow[t]{3}{*}{ \# of seats: } & \multirow[t]{2}{*}{5.0} & \multirow[t]{2}{*}{ Unnamed: 3} & \multirow[t]{2}{*}{ Unnamed: 4} & \multirow[t]{2}{*}{ Unnamed: 5} & \multirow[t]{2}{*}{ Unnamed: 6} & \multirow[t]{3}{*}{ Unnamed: 7} & \multirow{2}{*}{ Uype } & \multirow{2}{*}{$\begin{array}{l}\text { Assessme } \\
\text { Percentile }\end{array}$} & \multicolumn{2}{|c|}{ Assessmo.... } \\
\hline & & & & & & & & & Score & Score \\
\hline & & & & & & & & 1 & 1 & \\
\hline Student ID & Last name & First name & Grade & Teacher & Sex & Race & & & & \\
\hline 101 & Smith & John & 1 & Robinson & M & w & & 78 & 202 & 109 \\
\hline 344 & Hernandez & Nicole & 1 & Robinson & $F$ & $\mathrm{~L}$ & & 89 & 178 & 115 \\
\hline A4522 & Godkin & Liza & 1 & Robinson & $\mathrm{F}$ & w & & 56 & 165 & 99 \\
\hline
\end{tabular}

Figure 1. Sample spreadsheet for calculating local norms

Do this for every data point (the spreadsheet can handle up to ten) you want to include in the identification decision. Once you enter your student data, the spreadsheet will put each data point on a common scale (z-score) automatically.

\section{How to Combine Multiple Data Points}

Any time an identification decision is made using more than one data point, a decision must be made regarding how to combine those data points. Lakin (2018), Lohman (2005), and 
McBee et al. (2014), describe the three main ways to use multiple data points. The three combination rules they discuss are AND (high test score and high teacher rating must meet a threshold); OR (high test score or high teacher rating must meet a threshold); and MEAN (the average of test score percentile and teacher rating percentile must meet a threshold). The pros and cons of each method is beyond the scope of this manuscript. However, the AND or OR rules do not require much of the work of the spreadsheet. The AND rule is equivalent to rankordering based on each person's lowest score across all of the assessments considered. The OR rule is the opposite - equivalent to rank-ordering based on each person's highest score. Because each score is considered on its own (i.e. there is no averaging or putting multiple data points on a common scale), much of the work of the spreadsheet is not needed. For this reason, and because of reliability benefits the MEAN rule yields (McBee et al., 2014), our recommendation and our further example in the spreadsheet will apply the MEAN combination rule. Under this rule, all of the data points are put on a common scale before an average (the mean) of those data points is used for identification decisions.

How Much Weight Should Each Data Point Carry?

If you have multiple data points, you will also have to decide how much you want to weigh each data point. For example, maybe you want the ability test scores to count for twice as much as the teacher rating score or the academic achievement test score. If so, you would enter a "2" in the weight row (row 3 - see Figure 1 just below the "type" section) under "CogAT" and leave " 1 " for the other two. When calculating a local norm, the CogAT score will now have twice the influence on the final score as the other two data points. If you are curious about the impact of a particular data point, you can also enter "0". This will tell you what the resulting identified population would look like, under a local norm, if that data point was not included. You could also put a "3" as the weight for the teacher rating and then look at how the race or ethnicity of the identified students changes when teacher input is given more weight. However, we suggest making decisions about weights ahead of time and not based on looking at who is 
identified with each weighting option. Also, the spreadsheet will not identify any students with incomplete data, so you will want to be sure each student has a score for every indicator.

\section{Cut Scores or Number of Seats?}

You do not have to make this decision in order to implement local norms, but a common question is what cut score should be set on which you will make identification decisions? For example, in Illinois, students are identified if they score in the top $5 \%$ locally - the 95th percentile is the cut score on the local norm. A second way to determine who gets into a program is based on the number of spaces in that program - how many students can it accommodate? One main difference is that the cut score method could inadvertently reduce the number of students served if some students in the school have very extreme scores. In cell B1 of the spreadsheet, you can enter the number of seats available in the particular program. This does not change any of the resulting calculations. Instead, it just labels students as "yes/no" depending on their rank order. If there are five seats available, then the top five highest scoring students will be labeled as "yes" on the results tab. You can ignore the "\# of seats" component entirely and instead use the rank order result if you do not have a fixed number of spaces in a program.

\section{Enter Your Data}

Our example spreadsheet includes several student variables (e.g., ID number, name, grade, race), but all of these are optional. The essential data points are scores for each student on each data point. In our example, that means CogAT percentiles, achievement test, and teacher rating scale scores. Once you have decided on which data points or tests to include, how much to weigh each one, and how many seats you have in the program (again, optional), the next step is to get the data into the spreadsheet. As soon as you do so, the "results" tab will populate automatically with your local norms in the form of the "composite, rank, and selected?" columns. See Figure 2. The "composite" column is the average score of all of the scores you included. Remember, those were put onto a common (z-score) metric. The "composite" column takes the mean of the three data points. The "rank" column uses the composite score to list 
students from highest to lowest. The highest scoring student (on the mean composite of all of the data points) is listed as " 1 ". As the name should indicate, this is the same process or metric as high school class rank, where students are listed in order of their overall high school GPA. Finally, the "selected?" column reports which students would fill the number of seats specified in the "data" tab. If you reported five seats were available, then the "selected?" column will report "yes" for the five highest scoring students on the composite score. If you did not enter any number of seats, then this column will be blank and you will use the rank and composite columns to make your identification decisions.

\section{\begin{tabular}{ll|l} 
Instructions Data & Results & Calculations
\end{tabular}}

\begin{tabular}{|c|c|c|c|c|c|c|c|c|c|}
\hline \multicolumn{10}{|c|}{ Show rows with cells including: } \\
\hline Note: All in... & Unnamed: 2 & Unnamed: 3 & Unnamed: 4 & Unnamed: 5 & Unnamed: 6 & Unnamed: 7 & Unnamed: 8 & Unnamed: 9 & Unnamed: ... \\
\hline Student ID & Last name & First name & Grade & Teacher & Sex & Race & Composite & Rank & Selecte \\
\hline 101 & Smith & John & 1 & Robinson & M & w & $-0.2929016 \ldots$ & 5 & Yes \\
\hline 344 & Hernandez & Nicole & 1 & Robinson & $\mathrm{F}$ & $\mathrm{L}$ & $0.08334327 \ldots$ & 4 & Yes \\
\hline A4522 & Godkin & Liza & 1 & Robinson & $\mathrm{F}$ & W & $-0.7508969 \ldots$ & 6 & \\
\hline
\end{tabular}

Figure 2. Results of local norming using the sample spreadsheet

Connecting back to the rationale for local norms at the beginning of this manuscript, what you have done, specifically in the "rank" column, is identify the students most likely to require some additional level of challenge based on them being the furthest from what is typical in this grade in this school (the local norm). If you have measured quantitative reasoning, math achievement, and teacher ratings of gifted behaviors in math, then the lowest rankings (i.e. closer to 1) are telling you which students are the furthest above their peers in terms in the content area of math. A district coordinator could do the same procedure for any other content area. Local norms tell educators who is the most extreme among a group. It is then up to the 
educators to decide what kind or level of intervention would be necessary to assure that student is appropriately challenged.

\section{Other Options}

Earlier we mentioned the compromise rule where students are identified if they meet local OR national norm criteria. There is no way to implement or calculate national norms using the spreadsheet because the spreadsheet bases its norm on the data you provide. However, a district could follow the process we just outlined above to calculate a district-level norm (instead of just an individual building). Instead of entering data from a single grade in a single building, you would enter data from every student in a given grade in the district. The spreadsheet would then identify students based on a district norm. This form of a compromise identification policy would identify students who meet the district norm OR their local building norm. Similarly, a district could identify students based on nationally norm percentiles they receive from a test company OR based on the local norms calculated with the spreadsheet. Often these compromise rules can help a district transition from national norms to local norms or to assuage political concerns about who would no longer be identified under revised identification procedures.

The process we outlined using the spreadsheet is not the most efficient, primarily because you need to enter all of your data. If you have a large district, many data points you want to include, or a lot of missing data, this can get messy and time consuming. If you happen to work in a district that has a research or assessment office, you might consider asking someone in that office to help with this process. In some of the districts we have worked with, the research and evaluation team has been able to do this entire process and then just provide the advanced learning team with the list of identified students. Similarly, some test companies will provide you with local norm percentiles automatically or if you ask. This would only be a local norm percentile for one test, but perhaps that is what you are looking for. Our larger point 
is that if going through all of these steps on your own makes you nervous, often school districts have staff who can help with the number crunching.

\section{Conclusion}

Gifted and talented education services in $\mathrm{K}-12$ schools face two ongoing challenges.

The first is the rationale for the field's existence. Too often gifted programs or advanced learning opportunities exist without a clear rationale for why some students should receive those opportunities, but not others. The second is the problem of disproportionality or inequity within the populations of students served by gifted and talented programs. As an example, in 2016, African American students were only $57 \%$ as represented in identified gifted populations as they were in the overall United States K-12 population (Peters et al., 2019b). We believe implementing local norms would help address both of these challenges. As a method for selecting students in need of additional challenge, they make more sense and are easier to defend. Similarly, in empirical studies and in the real world of school districts, they have improved racial, ethnic, socioeconomic, ability and language proficiency equity. Local norms do not solve all problems (they fail to even fully resolve underrepresentation) and they are no magic wand. But they do represent a low-hanging fruit that would help move the field forward in meeting the educational needs of students.

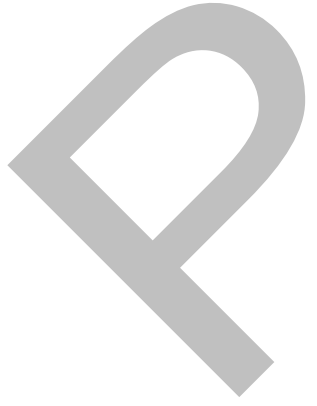




\section{References}

American Educational Research Association, American Psychological Association, \& National Council for Measurement in Education. (2014). The standards for educational and psychological testing. Washington, D.C.: AERA.

Arizona State Legislature. (n.d.). Gifted pupils; scope and sequence; annual funding. Retrieved from https://www.azleg.gov/ars/15/00779-02.htm

Carman, C. A., Walther, C. A. P., \& Bartsch, R. A. (2018). Using the Cognitive Abilities Test (CogAT) 7 Nonverbal Battery to identify the gifted/talented: An investigation of demographic effects and norming plans. Gifted Child Quarterly, 62, 193-209. doi:10.1177/0016986217752097

Illinois General Assembly (2005). Article 14A. Gifted and Talented Children. Retrieved from http://ilga.gov/legislation/ilcs/documents/010500050K14A-20.htm

Lakin, J. (2018). Making the cut in gifted selection: Score combination rules and their impact on program diversity. Gifted Child Quarterly, 62(2), 210-219. https://doi.org/10.1177/0016986217752099

Lee, L. E., Ottwein, J. K., Peters, S. J. (2020). Eight universal truths of identifying students for advanced academic interventions. In J. H. Robins \& J. L. Jolly (Eds.), Methods and materials for teaching the gifted (5th ed.). Waco, TX: Prufrock Press.

Lohman, D. F. (2005). Identifying academically talented minority students. Retrieved from https://nrcgt.uconn.edu/wp-content/uploads/sites/953/2015/04/rm05216.pdf

Lohman, D. F. (2009). Identifying academically talented students: Some general principles, two specific procedures. In L. V. Shavinina (Ed.), International handbook on giftedness (pp. 971-997). Berlin, Germany: Springer Science + Business Media.

McBee, M. T., \& Peters, S. J. (2019). Implementing local norms: A step-by-step guide 
(spreadsheet). Retrieved from https://osf.io/2pqmi/

McBee, M. T., Peters, S. J., \& Waterman, C. (2014). Combining scores in multiple-criteria assessment systems: The impact of combination rules. Gifted Child Quarterly, 58(1), 6989. https://doi.org/10.1177/0016986213513794

National Association for Gifted Children. (2019). A definition of giftedness that guides best practice. Retrieved from https://www.nagc.org/sites/default/files/Position\%20Statement/Definition\%20of\%20Gifte dness\%20\%282019\%29.pdf

New Jersey Department of Education (2018). N.J.A.C. 6A:8, Standards and Assessment. Retrieved from https://www.state.nj.us/education/code/proposed/title6a/chap8.pdf

No Child Left Behind (NCLB) Act of 2001, 20 U.S.C.A. § 6301

Peters, S. J., \& Borland, J. H. (in press). Advanced academics: A model for gifted education without gifted students. In T. L. Cross \& P. Olszewski-Kubilious (Eds.), Conceptual frameworks for giftedness and talent development. Waco, TX: Prufrock Academic Press.

Peters, S. J., Matthews, M., McCoach, D. B., McBee, M. (2014). Beyond gifted education: Designing and implementing advanced academic programs. Waco, TX: Prufrock Press.

Peters, S. J., Gentry, M., Whiting, G. W., \& McBee, M. T. (2019b). Who gets served in gifted education? Demographic proportionality and a call for action. Gifted Child Quarterly, 63(4), 273-287. https://doi.org/10.1177/0016986219833738

Peters, S., Rambo-Hernandez, K.E., Makel, M., Matthews, M., \& Plucker, J. (2019a). The effect of local norms on racial and ethnic representation in gifted education. AERA Open, 5(2), 1-18. https://doi.org/10.1177/2332858419848446

Plucker, J. A., \& Peters, S. J. (2016). Excellence gaps in education: Expanding opportunities for talented students. Cambridge, MA: Harvard Education Press. 
Plucker, J. A., Peters, S.J., \& Schmalensee, A. (2017). Reducing excellence gaps: A researchbased model. Gifted Child Today, 40(4), 245-250.

https://doi.org/10.1177/1076217517723949

Yaluma, C. B., \& Tyner, A. (2018). Is there a gifted gap?: Gifted education in high-poverty schools. Retrieved from https://edexcellence.net/publications/is-there-a-gifted-gap 